CuPAUAM 25.2, 1999, pp. 55-74

\title{
EL PROYECTO "LLAGÚ": LA EXCAVACIÓN INTEGRAL DE UN CASTRO EN LA CUENCA DE OVIEDO
}

LUIS BERROCAL-RANGEL

PAZ MARTíneZ SeCo

CARMEn RuIZ Triviño

Universidad Autónoma de Madrid

\begin{abstract}
Resumen
Este trabajo presenta los primeros resultados de la excavación integral del llamado Castiellu de Llagú, un castro ovetense conocido más en la literatura y prensa relacionada con problemas de conservación del Patrimonio Histórico y Arqueológico que por sus aportaciones científicas. Por ello, este proyecto, auspiciado por la Real Academia de la Historia y por el Principado de Asturias, pretende aprovechar las especiales circunstancias coyunturales que concurrieron en ello para lograr la exhumación y publicación completa de este yacimiento castreño, un primer referente "moderno" para las interesantes excavaciones sistemáticas que, en los territorios astures, vienen realizándose en las últimas décadas (Campa Torres, Moriyón, Chao de San Martín, San Chuís, etc.).
\end{abstract}

\section{Summary}

This paper presents the preliminary results of the complete excavations at the so-called Castiellu de Llagú, an Iron Age and Roman hill fort near Oviedo, in North-western Spain. The site, better know till now for the preservation problems it has presented than for the scientific results it has produced, has been fully excavated at last, thanks to a marciful change in socio-political circumstances. This dig report will hopefully be the first of a series of forthcoming publications on the various Pre-roman and Roman Asturian site which have been excavated in the last decades (Campa Torres, Moriyón, Chao de San Martín, San Chuís, etc.).

\section{EL CASTIELLU DE LLAGÚ, UN CASTRO EN LOS ORÍGENES DE OVIEDO}

En los privilegiados entornos de la capital asturiana, dominando los pasos y caminos que, atravesando el cauce del río Nalón, comunican por el sur la mal llamada "Cuenca de Oviedo" con las montañas mineras del Aramo, se emplaza este asentamiento castreño, viejo 
conocido de los ovetenses por las polémicas decisiones que han venido a destacar su reciente historia.

El Castiellu es un poblado típico de los denominados "castros asturianos", genéricamente integrable en la llamada Cultura castreña del Noroeste. Emplazado en las inmediaciones de Oviedo, concejo de Latores, a poco más de cuatro kilómetros del centro urbano de la capital, domina desde sus escasos $280 \mathrm{~m}$. de altura la margen derecha del río Nalón y sus pasos principales de Caces y Soto de Ribera.

A juzgar por la agreste y accidentada orografía, el poblado viene a ocupar una superficie de 1,4 ha., en la que destacan sus importantes restos defensivos, por lo que el Castiellu de Llagú fue descubierto por J. M. González y Fernández Valles y adscrito a la época romana tras prospecciones y hallazgos esporádicos, como un gran bronce monetal de Trajano (Maya y Mestres, 1998, 6; Estrada, 1997, 6; Maya, 1987-1988; González, 1976).

Su emplazamiento cercano a la ciudad de Oviedo y el subsuelo que lo caracteriza, rico en áridos, facilitó el inicio de una explotación de canteras, otra más de las muchas emplazadas desde la Edad Media en sus entornos, surtidores de la piedra de cantería de los palacios e iglesias ovetenses. Por ello, cuando el frente de avance de la cantera comenzó a dejar a la vista gran cantidad de construcciones defensivas, la polémica sobre las formas y maneras de actuar en salvaguarda de los intereses patrimoniales, por una parte, y de los económicos y laborales, por otra, propició su conocimiento público, no sin cierta dosis de escándalo social (Estrada, 1997, 8-9).

Para dar una respuesta oportuna a ambos intereses, aparentemente en conflicto, la Dirección General de Patrimonio del Principado encargó el pasado año 2000 la realización de un estudio integral sobre el yacimiento a la Real Academia de la Historia. De tal encargo se deriva la decisión de la RAH, a propuesta de su Anticuario Perpetuo Prof. Martín Almagro-Gorbea, de comisionar a los autores del presente escrito para realizar tal estudio que lógicamente, exige, la excavación integral de todo el yacimiento. Dicho proyecto se presentó ante a la Dirección General de Patrimonio del Principado el 14 de Junio de 2000, aunque la aprobación de su versión definitiva no fue efectiva hasta mediados del presente mes de Octubre, iniciándose la intervención arqueológica a comienzos de Diciembre hasta su culminación, previsible, para el mes de Mayo de 2001.

El trabajo debía partir de un profundo conocimiento del territorio circundante, así como de las labores y resultados de las excavaciones ya abiertas, en forma de campañas de urgencia, a lo largo de numerosos meses de los años 1994, 1996 y 1998, según un plan general de actuación previsto por la Consejería de Cultura del Principado y la Comisión de Patrimonio Histórico del Principado, que pretende obtener el mayor conocimiento posible sobre el poblado para tomar las decisiones oportunas para su conservación y divulgación.

Estas excavaciones, realizadas por Asturiana de Arqueología S.L. y Terra-Arqueos S.L. respectivamente, documentaron la presencia de importantes restos constructivos en el interior del castro, delimitado por fuertes murallas, torreones y accesos complejos. Numerosos artículos de prensa sucedieron a estos descubrimientos, aunque sus resultados científicos se conocen, prácticamente, por una breve síntesis de la campaña de 1998 (López González 
et alii, 1999) y por dos informes divulgativos de J. L. Maya y J. S. Mestres, y R. Estrada, respectivamente (1997 y 1998).

La oportunidad ofrecida por la Real Académica era clara. Con el reto de abordar en una campaña de seis meses de duración, semejante extensión arqueológica (sobre los $14.300 \mathrm{~m}^{2}$ ), y en unas condiciones sociales y naturales mínimamente catalogables de "difíciles", cabía obtener la memoria de la excavación integral de un castro asturiano, aportando una información de valía evidente para el conocimiento y desarrollo cultural de las poblaciones que ocuparon el territorio astur transmontano. Además, una mínima revisión de las estructuras constructivas y de los materiales exhumados en las citadas campañas de urgencia, demostraba el interés arqueológico de un yacimiento que, junto a otros contemporáneos de Asturias (Campa de Torres, Moriyón, Chao de San Martín.....), van permitido establecer las primeras síntesis del conocimiento sobre estos pueblos de época prerromana, romana y medieval[ ${ }^{[1]}$.

Cellagú, el Castiellu o Pico de Llagú como es vulgarmente conocido, se emplaza en las coordenadas $43^{\circ} 19^{\prime} 80^{\prime \prime} \mathrm{N}-5^{\circ} 54^{\prime} 00^{\prime \prime} \mathrm{W}$, hoja $\mathrm{n}^{\circ} 52$ PROAZA del M.T.N. de España 1:50.000. Ocupa una loma alargada de conglomerados de calizas y areniscas, orientado SWNE-SW y una cota máxima s.n.m. de 282 m. s.n.m. Esta es una altura "baja", propia del cinturón interior de la llamada "Cuenca de Oviedo" y, por lo mismo, proporciona un dominio visual muy determinado, sobre las ricas vegas que los meandros del río Nalón describen hacia su Oeste (W-NW), tras su convergencia con el Trubia. Por el Sur la visibilidad es mínima, obstruida por un cordal montañoso de alturas superiores a los 500 m. s.n.m. Esta estribación separa al yacimiento por su flanco sur del cauce del Nalón y sirve para encauzar hacia la desembocadura al subsidiario arroyo del Gafo, ésta a unos $2 \mathrm{kms}$. al Oeste del castro (fig.: 1.1).

Una posición tan específica sólo se comprende por la importancia del dominio de las vegas del Nalón hasta la desembocadura del Trubia, hacia las que se determina visualmente, condicionada por su misma línea de cota que, en esta dirección, presenta iguales o mayores alturas $(264,220,258,325,348 \mathrm{~m}$.), impidiendo hacia el Norte y Este toda visibilidad, más allá de sus propias laderas (fig. 1.2).

$\mathrm{E}$, incluso por el Oeste, la capacidad visual no alcanza más de $5 \mathrm{~km}$. en línea recta, aunque el interés se centra en los dos amplios meandros en los que desemboca el Gafo y cuya riqueza edafológica, en forma de depósitos aluviales aterrazados de tipo alfisols (Asensio, 1970; Mapa de suelos, 1988, 40), se confirma por la fuerte densidad de la ocupación agropecuaria actual y pasada (baños termales de Las Caldas, arte rupestre de las cuevas Las Caldas y La Lluera, etc.). Estos meandros, precisamente, son derivados de la resistencia que el límite del Anticlionorio herciniano del Narcea presenta al cauce del Jalón al Sur y al Oeste, siendo la orilla norte, que ocupa Llagú y otras estribaciones similares, el borde de la cobertera terciaria (Julivert y Marcos, 1981, 5).

[1] Un tema que fue centro del debate de los primeros Coloquios de Arqueología Castreña del Navia (Octubre de 2000), a cuyas actas en prensa, editadas por Ángel Villa Valdés, remitimos y donde incluimos un avance de la problemática inicial de este proyecto. 


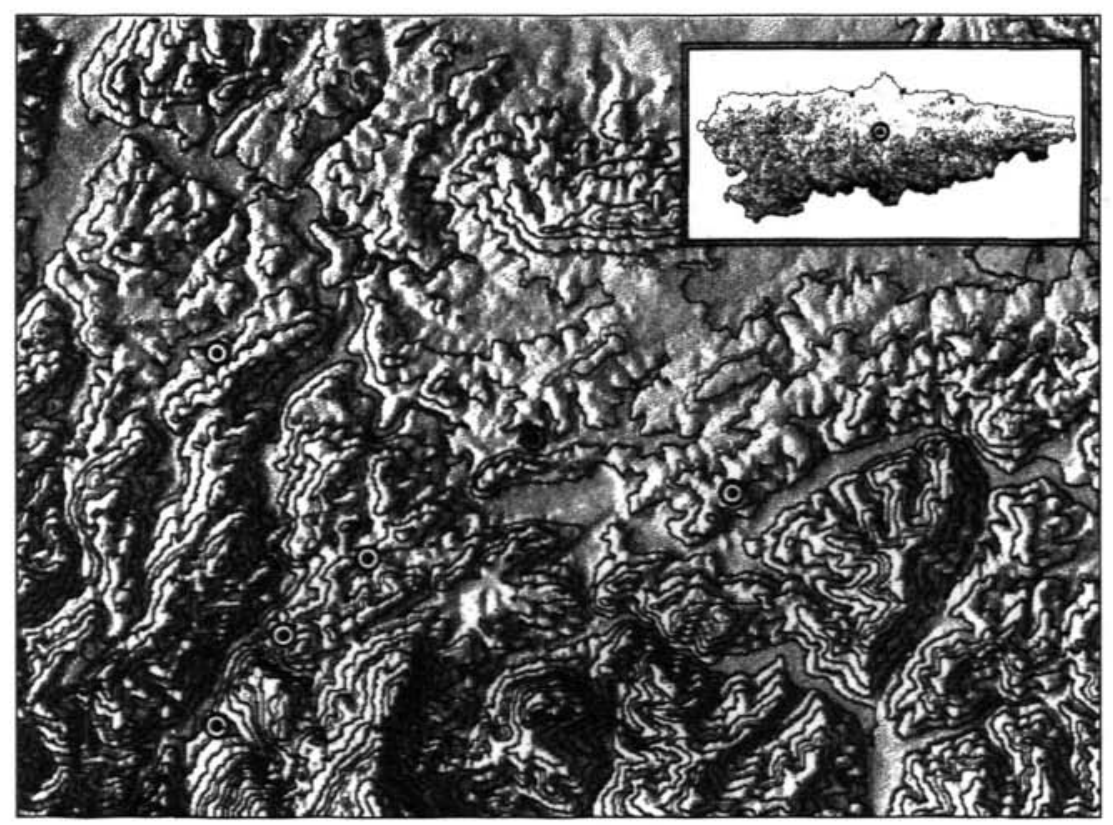

Figura 1.1. Localización del emplazamiento del Castiellu de Llagú (๑), en plena "Cuenca de Oviedo", y su relación con los castros más cercanos

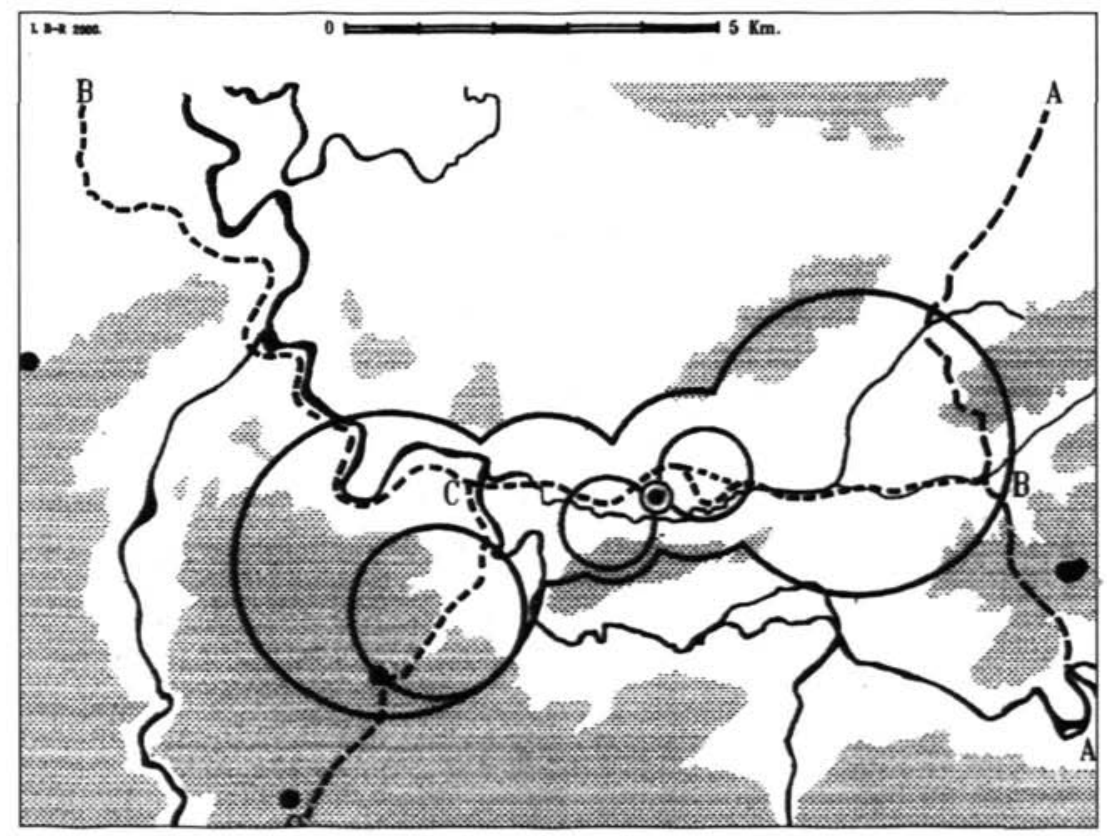

Figura 1.2. Dominios de visibilidad desde el Llagú y trazados de los caminos propuestos. 
La capacidad agro-pecuaria de estas tierras justifica que, en ellas, se localice la mayor concentración de población de los entornos, por encima incluso de la registrada a lo largo de las carreteras regionales cuando, aquí, la única trama de vías de comunicación es de tipo local y limitado. En la otra orilla, la confluencia del Trubia supone otro manchón aluvial de importancia, quizá la razón del emplazamiento de otro castro en el Cerro de San Julián, al nordeste de Belandres (concejo de Grado: Estrada, 1999, 316), tan alejado de esta confluencia como Llagú de las vegas del Gafo.

Sobre éste y el Nalón, los vados gemelos de Caces y de la Estación de Puerto son centro de atención desde el Llagú, suponiendo que por ellos transitaría gran parte del mineral extraído en las minas de cobre de Aramo, a unos kilómetros al Sur, en el concejo de Riosa. De su beneficio no caben dudas por los hallazgos de crisoles, moldes, escorias, rebabas, y "hoyos de fundición", restos de pequeños hornos con crisoles hallados en no pocas estancias del castro (fig.: 5.1; López González et alii, 1999, 239; Maya y Mestres, 1998, 7).

Un segundo objetivo focal desde El Llagú se encuentra por su Oriente, siguiendo las vías de comunicación nacionales que conectan Oviedo con la Meseta. Bajo ellas o en su paralelo, a 4,5 Km lineales desde Llagú se propone la vía romana de León a Gijón por el puerto de la Carisa, de camino hacia el vicus viarii que fue Lucus Asturicum (Lugo de Llaneras: Fernández Ochoa, 1981, 266 y ss., esp. 269; 1982). Aunque sobre testimonios toponímicos e históricos, como el medieval Camín Real de Castilla (tramo desde Olloniego a Oviedo), esta propuesta es bastante coherente con el camino de comunicación principal potenciado por los romanos, en parte por las escasas posibilidades de tránsito que la abrupta orografía ofrece por estos lugares. Para Carmen Fernández Ochoa, quien realmente estudió su trazado, "cruza el Nalón por este lugar [Olloniego] y por el Portazgo bordea el castro del Picu Llanza hacia la Venta del Aire - S.Miguel - Los Molinos - Cajigal - Los Prietos Los Corzos - La Manjoya - y penetra en Oviedo por el actual barrio de San Lázaro (1981, 269).

La relación visual con Llagú es, sin embargo, limitada al horizonte, siendo difícil, por aguda que fuera la vista, concebir una capacidad de control real sobre la citada vía. Quizá por ello, la relación aparente entre ésta y la disposición de la trama urbana de Llagú, enfrentada sobre su ladera Sudeste sea, tan sólo eso, aparente. Esta disposición SE parecería adecuada para dominar la visual sobre el vado del Nalón por Soto de Ribera, a poco más de $2 \mathrm{~km}$. en esta dirección, pero las estribaciones superiores de la Sienra se interponen entre el yacimiento y el conocido vado por donde cruza la Nacional 630.

Mucho más coherente es defender que esta disposición, entre otras razones, se deba al dominio de un punto interseccional, él del ramal secundario que, desde el corazón del Narcea (concejo de Proaza.....) recogería el mineral de cobre extraído de los yacimientos primarios de sus sierras, para encaminarlo por el vado del Caces hacia Lucus Asturicum, lugar central de la civitas asturum (González Rodríguez, 1997, 46; Fernández Ochoa y Morillo, 1999, 82). El control sería compartido con otra serie de castros de similar entidad, como el mismo "Picu Llanza" desde el margen oriental de dicha vía, como se van localizando una serie de asentamientos castreños, equidistantemente emplazados cada $5 \mathrm{kms}$. lineales a lo largo de la vía del Aramo, por Santo Adriano hasta el Trubia: en "Pico Siones", 
"La Peña", etc., precisamente por donde, entre abruptas montañas, penetra la mirada desde Llagú (fig. 1 y Berrocal, Martínez Seco y Ruiz Triviño, en prensa).

Así, la disposición de la trama urbana de este castro se entendería en los sistemas de organización del territorio impuestos por los romanos, encaminados a la explotación de los distritos mineros (Fernández Ochoa y Morillo, 1999, 60; Carrocera; 1995, 59; SánchezPalencia, 1995), en la línea de otros castros prerromanos fuertemente favorecidos a partir del siglo I d.C. (Villa, 1999, 120-121; Camino, 2000).

Geológicamente, El Castiellu de Llagú se enclava en el borde mismo de la Zona Cantábrica y, especialmente, en el de la llamada Cuenca de Oviedo del surco prelitoral asturiano. Litológicamente, tal posición se manifiesta en las tierras más occidentales de base arenisca terciaria y caliza paleozoica, con formaciones orográficas alomadas que sirven de camino para las corrientes del Nalón, frente al dominio abrupto y escarpado de las pizarras del Antiforme del Narcea. Las areniscas se documentan formando conglomerados con arcillas rojas carboníferas, mientras las calizas pertenecen a las formaciones de montaña (Alonso et alii, 1991, 1 y 30-32). Areniscas y calizas, áridos en general, son explotados en canteras que, tradicionalmente, han abastecido las necesidades constructivas de Oviedo, de las que se localizan varias en sus inmediaciones sudorientales. Interesante resulta el topónimo Ferreros, en el dominio sobre la vía León-Gijón, en relación con viejas extracciones de hierro.

Como en el resto del SO del territorio ovetense, el clima se define en la estación agroclimática de Soto de Ribera, incluyéndose en la categoría climatológica "mediterráneo marítimo templado" de la clasificación de Papadakis (Mapas de suelos, 1988, 12 ss). Esta consideración viene comprendida, fundamentalmente, por el factor de moderación que supone la cuenca de Oviedo, sin temperaturas extremas y con una media anual de $14^{\circ} \mathrm{C}$. El índice pluviométrico inferior a $1100 \mathrm{~mm}$. supone unas cantidades similares a las costeras y algo inferiores a las propias de estas latitudes más interiores, favoreciendo terrenos con praderas, pomaradas y, en caso de las llanuras aluviales aludidas, con huertas y demás cultivos intensivos a lo largo de todo el año, incluyendo cereales de siembra primaveral, como el mijo o panizo. En general se trata de un paisaje alterado, con una huella antrópica grande -especialmente remarcada por las "mordidas" de las canteras antiguas y modernas-, donde la cubierta vegetal ha sido limitada a las especies cultivadas, aunque quedan manchas aisladas de Quercus robur, Q. Ilex, Q. petrea y Fagus silvatica, básicas del bosque mixto propio de esta comarca.

En suma, El Castiellu de Llagú representa el asentamiento estable más antiguo conocido por excavaciones entre las ocupaciones que darán origen a la capital del Reino asturiano. Su localización se define con claridad en una trama de poblados similares que, perfectamente coordinados, debían controlar el tránsito y los accesos a los recursos de la Cuenca de Oviedo, conocido paso natural entre el litoral y los pasos principales de montaña (Fig. 1). Es de reseñar que Llagú ocupa una altura equidistante de las desembocaduras del Trubia y del Caudal en el Nalón, vector axial de una comarca "parte sustancial de la llamada cuenca central hullera, en una céntrica posición dentro de las comarcas asturianas y dispone de abundancias de aguas y bosques a la vez que de tierras llanas" (Mapa de Suelos, 1988, 29). 


\section{EL CONOCIMIENTO ARQUEOLÓGICO DE UN CASTRO ROMANIZADO}

Como se ha comentado, la ocupación del Llagú se va revelando especialmente concentrada en su vertiente sur-sureste, precisamente aquella emplazada frente al alargado cordal montañoso de la Sienra, del que le separa el embarrancado arroyo Gafo. Pese a sus pronunciadas paredes, bajo la loma aplanada y buzada, se localizan poderosas obras de fortificación que incluyen, al menos, dos líneas de murallas aterrazadas, dominadas por una torre central, de planta circular, y sendos bastiones localizados en los extremos de esta vertiente.

Estas líneas de fortificaciones sirvieron para proteger el acceso lento de un camino de carros claramente localizable junto y a lo largo de sus terrazas y murallas, serpenteando hasta el extremo Norte, donde tuerce acusadamente para converger con otro acceso, desde el Noroeste, en forma de aparente foso, y proceder a la entrada principal del castro.

El análisis superficial y los primeros resultados de la excavación integral de esta zona demuestran que sus construcciones responden a un patrón muy parecido a perfilado para los escasos castros conocidos con cierta extensión, eso sí, en el Oeste de Asturias, especialmente representados por Coaña (García Bellido, 1942). Así una puerta en el extremo norte del poblado permitiría el acceso y la salida general, incluidos carros, fuertemente defendida y destacada por torres y bastiones a uno y otro lado, y dominada por la cercana acrópolis, sobre el promontorio rocoso más alto de Llagú (Fig. 2). En esta, y en su entorno, los escasos restos de edificios singulares, incluidos una posible sauna, comienzan a desvelarnos una realidad urbana menos "sorprendente" de lo que se hubiera esperado en un castro tan oriental como el Castiellu de Llagú. Frente a la puerta, a $200 \mathrm{~m}$. al Nordeste según las prospecciones realizadas, una pequeña elevación sirvió para emplazar un pequeño fortín, torre múltiple o antecastro que cerraba, por detrás, el sistema de seguridad aplicado a la entrada principal.

El perímetro amurallado pudiera confirmarse prácticamente al completo, incluyendo los límites Oeste y Norte, aunque los taludes y afloramientos rocosos parecen haber servido como disuasores naturales para cualquier acceso. Otra posible puerta, de menor entidad, se presume del estudio del terreno en el extremo SE, paralela y contrapuesta a la principal referida. En medio, entre las potentes murallas, el equipo responsable de la campaña de 1996 localizó un acceso menor, pedestre y escalonado, que fue condenado por la construcción posterior de una puerta monumentalizada de la muralla romana (Maya y Mestres, 1997, pg. 7; Ruibal y González Álvarez, 1996). Como es obvio, una planta tan alargada no puede excluir otros accesos complementarios como las poternas, que facilitaran el tránsito y la comunicación exterior de un espacio tan reducido.

En realidad, de su interior se presumía un esquema ocupacional similar al planteado por J. Camino a partir de los castros occidentales, un terreno considerablemente amplio a su alrededor sin construcciones reconocibles, dedicado quizá a la estabulación del ganado, y una franja sobre las murallas densamente ocupada por las casas de planta redonda (Camino Mayor, e.p.). Así parecía confirmarse de las intervenciones ya realizadas y del reco- 
nocimiento superficial, aunque tras la excavación de gran parte de estos espacios puede avanzarse que el supuesto espacio sin ocupar dedicado al ganado presenta construcciones y cerramientos que debían responder a otras funciones más complejas.

Sí se confirma que la mayoría de las construcciones de hábitat y defensas ocupaban densamente un arco meridional, protegido de las borrascas y vientos nordoccidentales. Y, a juzgar por los resultados de las primeras intervenciones realizadas en este sector, la concentración de cabañas y construcciones es muy superior a la quincena de casas identificadas entre las intervenciones de 1994, 1996 y 1998.

Las campañas de 1994 y 1996 se centraron en los límites exteriores de las murallas y en sus aterrazamientos, así como en la recuperación en extensión de la gran torre central y en las construcciones asociadas a ellas. En 1998 se intentó lograr mayor información sobre las secuencias ocupacionales a partir de sondeos dispersos longitudinales y transversales abiertos al interior del poblado, porque sus límites exteriores, o bien habían sido ya excavados o bien se encuentran bajo las zonas de acceso de la cantera, "sedimentos en los que no se pudo intervenir, pero que sin duda podrían ofrecer mayor información respecto a la fundación y desarrollo de los elementos defensivos y su relación con la ocupación del poblado y su secuencia cultural" (López González et alii, 1999, 242).

En esta zona interior, la excavación de 1998 documentó hasta un total de 11 cabañas distribuidas en tres sectores, Occidental, Central y Oriental, que en general presentan estratos de abandono muy removidos entre hiladas de cimentación y sobre capas, escasas y livianas, conservadas in situ.

Entre los tres sectores se distingue, al menos, una periodización con otros tantos niveles de ocupación: uno, primero, escasamente conocido por una cabaña hallada en el extremo oriental, cerca de la puerta principal del poblado, asociada a materiales romanos del siglo I y II, manifestando el momento final de la ocupación antigua del castro. Otro, segundo, mejor documentado, con una cronología previa del siglo I d. C., y un tercero, sin secuencias estratigráficas, que ha sido adscrito a época prerromana.

Sobre ellos, el presente proyecto ha planteado una actuación integral, donde, a partir del conocimiento general de las secuencias de ocupación y de las características estratigráficas del poblado, se opta por una aplicación de la "estrategia de área abierta", combinada para un desarrollo más ágil en las zonas propicias con la técnica de "secciones acumulativas” según definió P. Barker en Techniques of Archaeological Excavations (1977, Harris, 1989, 38).

La estrategia propuesta es por lo mismo de carácter complejo, estableciendo la utilización de tres sistemas consecutivos (Fig. 2):

1. Sistema de cuadrículas y transectos: las primeras diseñadas para la excavación inicial de la superficie global del castro, pero que se ven aplicados con exclusividad en aquellas zonas superiores donde la potencia total del substrato es tan escasa como son los restos constructivos localizados. Se ejecuta con la apertura inicial, en cuadros de $5 \times 5 \mathrm{~m}$., con testigos de $1 \mathrm{~m}$. al sureste y, alternativamente por filas, al suroeste y nordeste respectiva- 


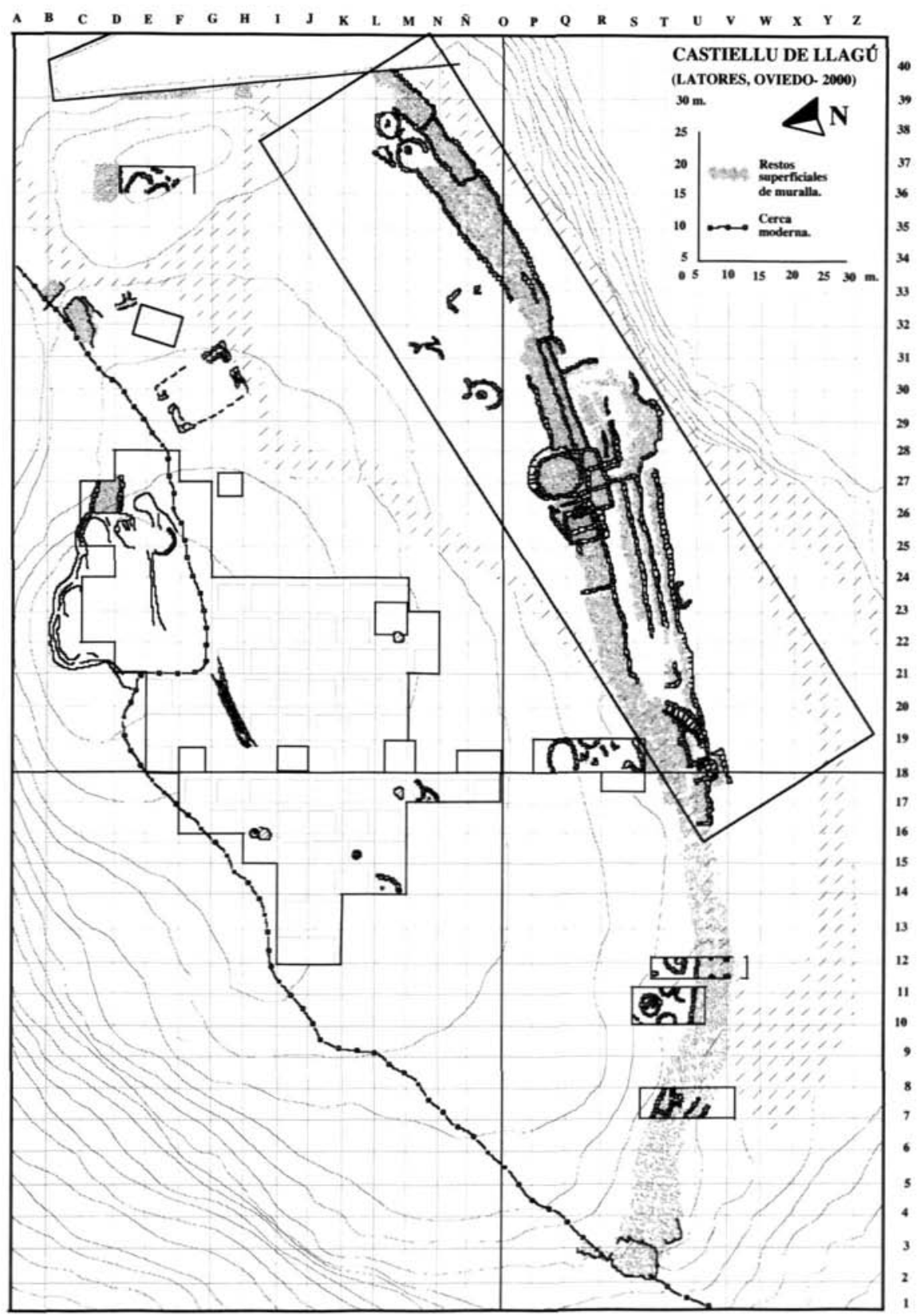

Figura 2. Planimetría general de LLagú (2000), realizada a partir de los restos superficiales, y de los constatados tras los primeros meses de excavaciones junto a los descubrimientos en 1996 y 1998 (estos dos según Ruibal t González Álvarez, 1996, y López González et alii, 1999, respectivamente) 
mente. Las líneas de referencia longitudinales serán los límites referidos de las cuadrículas, contabilizando las zonas de testigo. Las cuadrículas, según el método y la terminología utilizada, se denominarán con un sistema combinado alfanumérico en mayúsculas, derivado de la aplicación de un esquema tradicional de coordenadas cartesianas, dando a las abscisas (NE-SW) las letras del Abecedario ên mayúsculas y, al eje de ordenadas (NW-SE), el numerario arábigo a partir del 1 en adelante. Los ejes de referencias se cruzan en la cuadrícula 018 , dando una superficie teórica aproximada de $15.000 \mathrm{~m}^{2}$ (600 cuadrículas), de los cuales $5.000 \mathrm{~m}^{2}$ corresponden a las campañas de 1994 y 1996, y $500 \mathrm{~m}^{2}$ a la del 1998. Los transectos se han establecido sólo para algunas zonas de interés exteriores al perímetro amurallado. Concretamente se considera adecuada su aplicación sobre los accesos a la puerta principal entre ésta y el antecastro.

2. Sistema de "área abierta": se impone en los estratos arqueológicos cuando se definen las primeras estructuras arquitectónicas de importancia y en las que la conservación de testigos se limitará sólo a aquellos que sean de interés para la interpretación de las unidades arqueológicas. Las referencias de localización seguirán tomándose a partir de los límites de las cuadrículas.

3. Sistema de secciones acumulativas: en las capas más complejas, insertas en ámbitos arqueológicos reconocidos. Se valora el concepto de unidad arqueológica en planta, básicamente, reseñando las secciones según se excavan, con independencia de que pueda conservarse algún testigo significativo. Las cuadrículas inicialmente propuestas sólo servirán para la toma de referencias longitudinales. Las unidades o ámbitos arqueológicos, referidos a estancias internas y espacios externos, se denominan con las mismas siglas en mayúsculas que las cuadrículas.

En todas ellas, los procedimientos de excavación primarán el levantamiento de estratos naturales sobre capas artificiales, siguiendo las pautas ya comprobadas, que son relativamente claras. No obstante, la agilidad necesaria en una obra de la envergadura de la propuesta en este proyecto permitiría la bajada artificial de ciertos sectores, aunque siempre tras la apertura de sondeos previos que guíen y aconsejen la utilización de este sistema.

Todas estas aplicaciones técnicas continuarán los sistemas de nominación utilizados anteriormente, partiendo de la capa superficial, 1, 2, 3,... para las secuencias de estratos o capas naturales, que se irán individualizando con letras minúsculas, de manera que, "Ia" corresponde a una capa de deposición, "1b" a otra de destrucción, "1c" a una tercera de ocupación específica, y "1p" al pavimento de la secuencia. Otros elementos interfaciales, como muros, fosos, hogares, etc. serán denominados con letras minúsculas o mayúsculas simples, independientemente de la secuencia en la que se construyeron o se utilizaron. En estos, cuando se documenten diferentes capas antrópicas, se aplicará otro componente en forma de letra minúscula, tercero en los pavimentos, segundo en los elementos verticales u horizontales. Un foso, o un silo, no se considerará un estrato natural o una secuencia de estratos, sino un estrato antrópico, con sus divisiones internas y con una posible identificación secuencial si fuese el único resto de un nivel de ocupación, pero siempre con el valor condicionado a su consideración de "conjunto de capas artificiales". 
Cada secuencia estratigráfica se representará con un número arábico, que corresponde a un nivel de ocupación ${ }^{[2]}$, partiendo de " 0 " para la época actual y moderna (materiales rodados, en principio), "I" para los restos de época altoimperial sin muralla, "II" imperial amurallada, "III" prerromana, etc.

Es importante tener en cuenta que la relación entre secuencias y niveles de ocupación no tiene porqué ser directa, aunque normalmente se constate como tal, porque pueden existir niveles sin secuencias de estratos, p.e. el nivel "III" sólo se ha documentado en cuencas de deposición, entre las irregularidades de la roca madre de diferentes sitios del yacimiento.

En general hay que precisar que, excepto en el citado arco sudoriental, donde las potentes murallas han servido de parapeto para la erosión eólica y pluvial facilitando la concentración de potentes estratos de deposición, la mayoría, resultantes de remociones naturales y, por lo mismo, de difícil interpretación, el resto del yacimiento prácticamente presenta una débil capa térrea, la estrictamente necesaria para el crecimiento de las abundantes herbáceas que tapizan toda la loma. Por el contrario, sobre las murallas y las cabañas del referido arco crecieron arbustos y, en los extremos, algunas encinas y coscojas de considerable porte.

Un avance a la lectura ocupacional del castro debe aclarar que, aunque sin construcciones reconocidas, se han localizado un interesante grupo de materiales modernos, fechados por un conjunto de tres monedas, en el siglo XIX, pero que bien responden a una ocupación productiva más antigua mantenida hasta mediados del XX (monedas, botones y callos de bueyes, fundamentalmente). Esta ocupación, " 0 ", debe relacionarse con el uso tradicional del cerro como cantera, depósito de sillarejo y mampuesto para la construcción de las casas de Latores y las inmediaciones. Desgraciadamente es fácil suponer que tal beneficio se realizaba con el desmantelamiento continuado de las construcciones arqueológicas del Llagú, a la manera de lo ocurrido en otros yacimientos peninsulares de renombre, como Ulaca.

El nivel de ocupación I puede catalogarse como el período de final de la habitabilidad en continuidad del cerro, de clara época romana, con el módulo de vivienda de planta circular tradicional pero, al parecer, sin la necesidad de amurallamiento (cabaña $\mathrm{H}$ se construye sobre la muralla anterior). Los materiales apuntan fechas flavias y antoninas.

Del segundo nivel, en el Sector occidental se reconocieron hasta cinco de estas cabañas (A-E 1998) de pequeñas dimensiones, zócalo de piedra y paredes de paja, y madera, emplazadas a lo largo de zonas de paso, a veces empedradas. Sólo en una se documentó un hogar por lo que, a juzgar por los numerosos restos de fundición de bronce (crisoles, moldes, tortas y lingoteras) y la escasez de materiales cerámicos significativos, sus excavadores optaron por considerarlas lugares de trabajo, con una cronología posterior a una pri-

[2] Lo que Harris denomina período de formación, en nuestra opinión con no mucha fortuna, por haber tomado el término directamente de la Geología: Harris, 1991, 100 ss. 
mera línea de muralla, adscrita al siguiente nivel, III, que se aprovecha como zócalo para la construcción de la cabaña E. (López González et alii, 1999, 238-239).

En el Sector central, las cabañas (F y G 1998) de este nivel II adquieren mayores dimensiones y el trabajo de aterrazamiento realizado para su construcción testimonia un interés constructivo complejo, pero los trabajos de la cantera y, especialmente su pista de acceso, han removido totalmente los posibles estratos inalterados, no dejando más que estos trabajos de cimentación. Mejor conservadas, por la cobertura de derrumbes modernos, se localizan tres cabañas (H-J) más, en el Sector oriental. Dos de ellas (I-J) responden a similares características "zócalo de grandes piedras sobre una superficie horizontalizada con rellenos arcillosos" y están asociadas a la muralla en este tramo, y a materiales romanos y de tradición indígena del siglo I d.C. (150 frag. TSH y 50 frag. TSG; cuencos Isings 3 acostillados; cerámicas a torno, o a mano, bruñidas o estampilladas castreñas: ibídem, 246) - (Figura 3). La tercera cabaña (H 1998) se construye sobre los derrumbes de las anteriores y de la misma muralla y, a juzgar por sus materiales, responde al citado último momento de ocupación, 1, entrado ya el siglo II d.C., donde no parece contemplarse la necesidad de muralla alguna.

En este mismo sector, la muralla que denominaremos " $\mathrm{A}$ ", asociada a este nivel II, muestra "una clara diferencia constructiva con la reconocida en los otros dos sectores". Estratigráficamente está relacionada con las casas romanas del siglo I, aunque pudiera ser una remodelación de la muralla "B", prerromana. Esta consideración se tiene en cuenta, pese a no aclararse su relación con los materiales indígenas de las capas más inferiores, que se dan como desconectados (ibidem, 241-243, láms. IV-V), porque coincide con la interpretación proporcionada por los arqueólogos encargados de las campañas anteriores, quienes documentaron la amortización de un acceso anterior, probablemente prerromano, con una nueva puerta, otra línea exterior de muralla y un amplio torreón de $7 \mathrm{~m}$. de diámetro, con escalera de caracol externa y compartimento adosado (Maya y S. Mestres, 1998, 7). De igual forma, una vez realizada la limpieza de los restos excavados, se puede confirmar con facilidad ambas diferencias de paramentos y calidad edilicia. Sencillamente, la muralla "B" está construida con mampuestos a seco o trabajos con barro, mientras que, en la muralla "A", esta mampostería ha sido sustituida por sillarejos rectangulares de proporciones regulares, en disposición de opus quasi quadratum ${ }^{[3]}$.

El nivel anterior, $\mathrm{n}^{\circ} 3$, no está representado por secuencia estratigráfica alguna hasta el presente sino por cuencas de deposición y, quizá, por la citada fase más antigua de la fortificación, la muralla "B".

En el Sector occidental y central, esta aparece sin su cara exterior, aunque puede documentarse su construcción a base de una sucesión de módulos "a los que parece adosarse un lienzo exterior que los unifica" (López González et alii, 1999, 240). Los niveles de ocupación asociados son desconocidos, excepto por las hiladas de cimentación, de las que se llegan a conservar hasta cuatro del paramento interior en el Sector central. Solamente en

[3] Con medidas de $15 \times 7 \mathrm{~cm}$. fundamentalmente. 


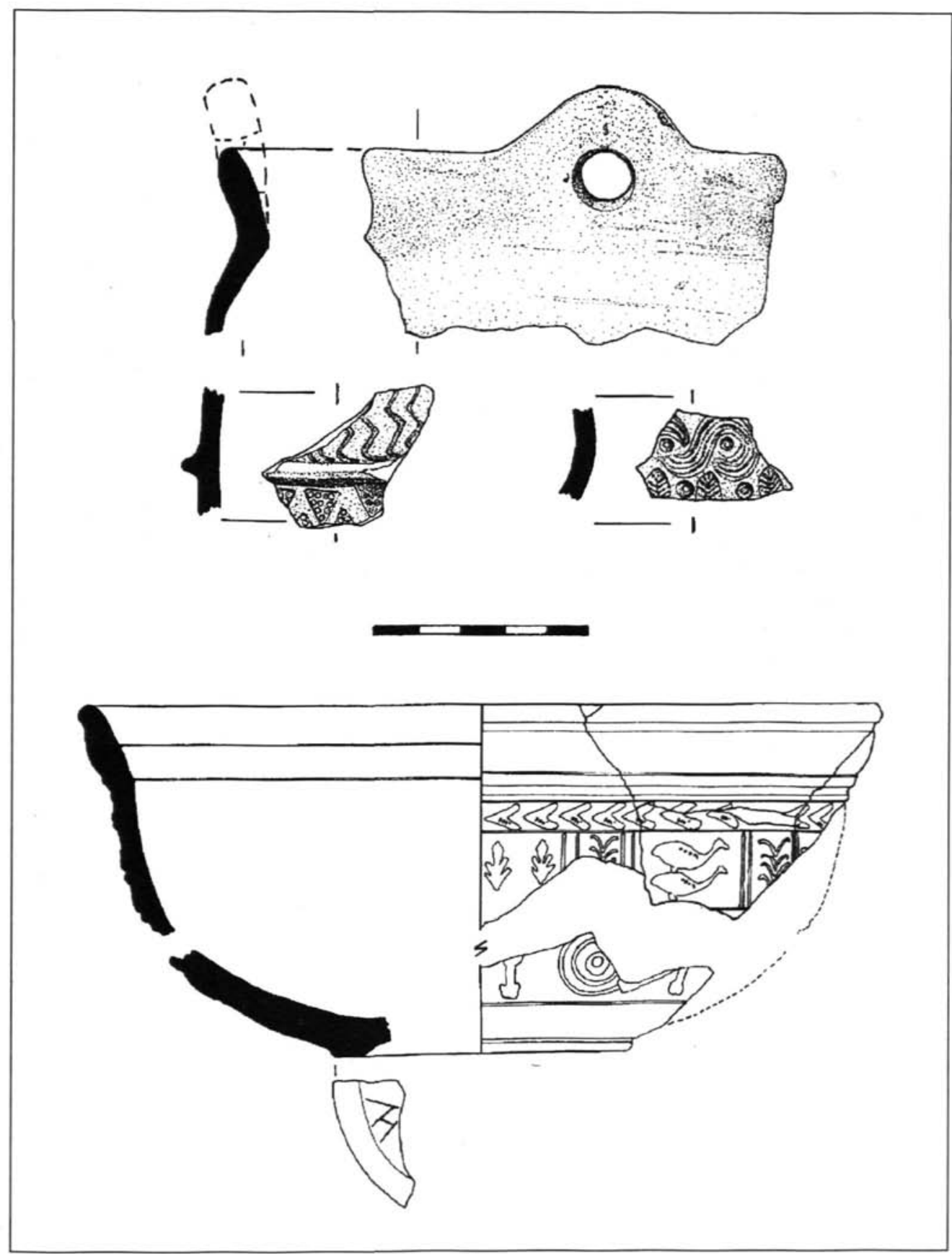

Figura 3. Cerámicas castreñas y de terra sigillata, a partir de Ruibal y González Álvarez, 1996. 
el Sector oriental, desconectados de la base de la muralla 2, aparecen depósitos "que contienen únicamente materiales indígenas" (López González et alii, 1999, 241), pero cuya indefinición cronológica no permite tener la certeza de tal afirmación.

En anteriores campañas, el núcleo de este sistema defensivo fue excavado en su totalidad, obteniéndose un lienzo descrito como de "módulos y espina central" de más de 50 $\mathrm{m}$. de longitud, apoyado en tres líneas de aterrazamientos sucesivas y con una escalera de 22 peldaños en su acceso. Esta escalinata y parte del lienzo fueron soterrados por la muralla de época romana (Maya y S. Mestres, 1998, 7 y lámina). La limpieza intensiva de lo conservado tras la excavación $n^{[4]}$ demuestra lo acertado de estas apreciaciones, constatándose los referidos aterrazamientos bajo la muralla que corresponde a la fase " $\mathrm{B}$ ". El nervio, en realidad, es el paramento interior de la cortina de doble cara en emplekton que configura el lienzo, al que se le adosa, por este lado, otra cortina de menor anchura y única cara al interior, la que pasa ser la efectiva de la muralla. Su función es la de contener el relleno de estas gruesas cortinas, asentadas a seco sobre un terreno rocoso e inclinado.

Para determinar la fecha de uso de esta muralla más antigua se obtuvieron hasta trece muestras de dataciones radiocarbónicas, analizadas un primer grupo por el Laboratorio de Radiocarbono de la Universidad de Barcelona (Maya y Mestres, 1998, 9), otro segundo por el Instituto Rocasolano del CSIC Madrid (López González et alii, 1999, 244). De ellas se han logrado fechas coherentes para un momento de ocupación, si no de fundación, de los siglos IV y III a.C. (Cal BC 390-209, como promedio para los primeras, y 359-53, 536-252, 761-393, rangos de las segundas).

La coincidencia de ambos muestrarios, y la significativa elección de algunas de las muestras (como las $\mathrm{n}^{\circ}$ 5, 9 y 10 de Maya y Mestres), permiten albergar pocas dudas acerca de la ocupación prerromana del castro y tampoco parecen existir inconvenientes mayores para suponer su relación con la fase más antigua de las murallas, especialmente a partir de las dataciones obtenidas para otras similares en yacimientos como Moriyón II, Chao de Sanmartín, y Campa de Torres (Carrocera y Camino, 1996, 58; Villa, 1999, 120; Maya y Cuesta, 1999, 133; Camino, 2000).

Además de los fragmentos cerámicos, especialmente en el Sector oriental, se han recogido numerosos elementos ordinarios de hierro, bronce, madera y hueso, así como materiales líticos trabajados, significativamente procedentes del llamado arco sudeste, el ocupado densamente y excavado entre 1994 y 1996. De ellas, excepto un posible broche discoidal, prácticamente todos los que aportan fechas claras se insertan en las ocupaciones 2 y 3 , quedando la fase prerromana relegada a materiales cerámicos indígenas cuya perduración no permite tener certeza sobre el momento de uso o de cocción (Fig. 3).

Del resto destacamos un interesante grupo de fibulas, muy coherentes en las relaciones y contextos históricos en las que se encuadran (fig. 4). Fíbulas romanas de bronce

[4] Es preciso recordar que estos restos fueron salvajemente destruidos, en una acción anónima e inesperada, acecida durante los momentos más tensos de la polémica que caracterizó el yacimiento a lo largo de los años 1997 y 1998. 


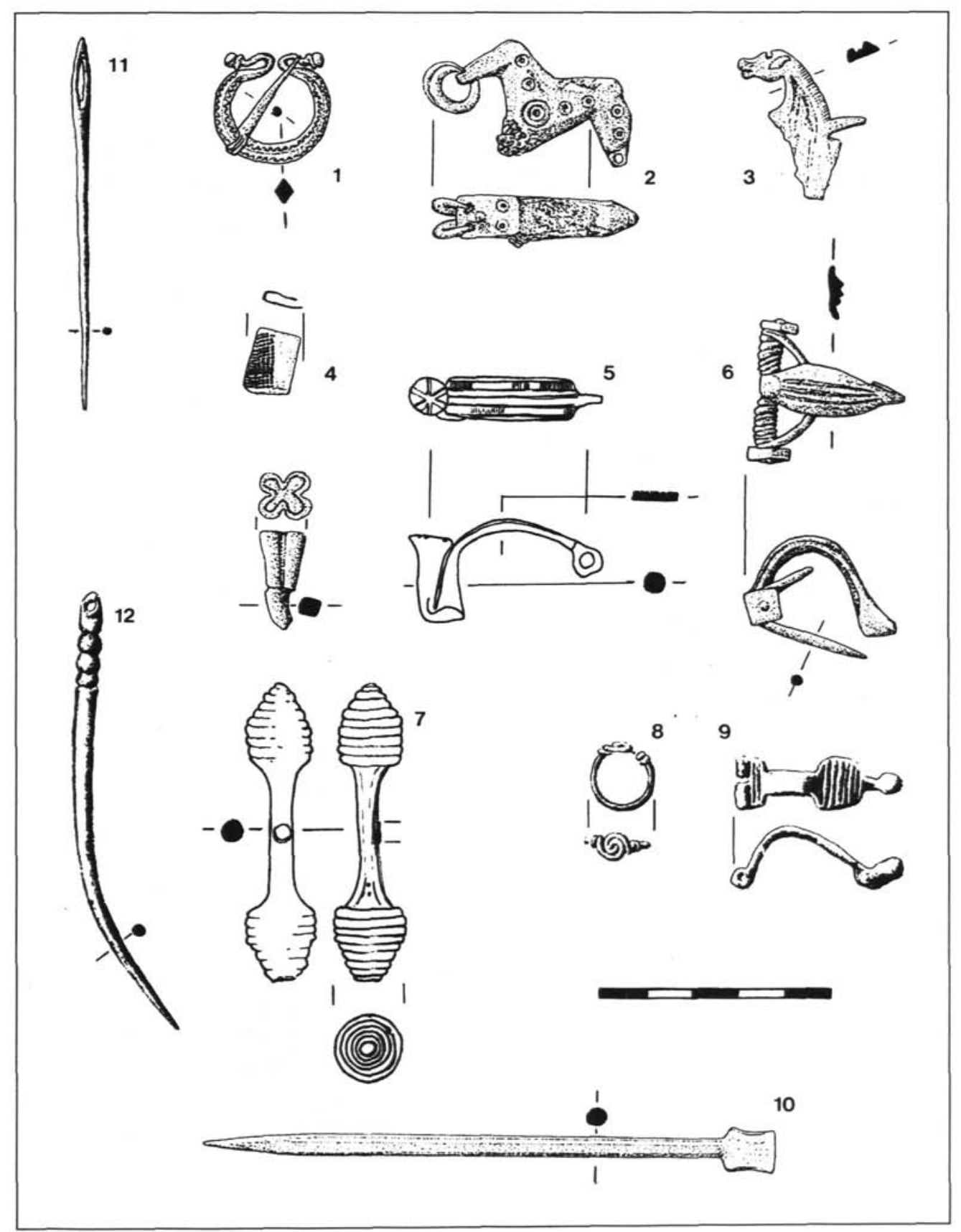

Figura 4. Piezas metálicas: 1-5 y 7 según Ruibal y González Álvarez, 1996; 6 y 8 inéditos; 8 y 13 de López González et alii, 1999 

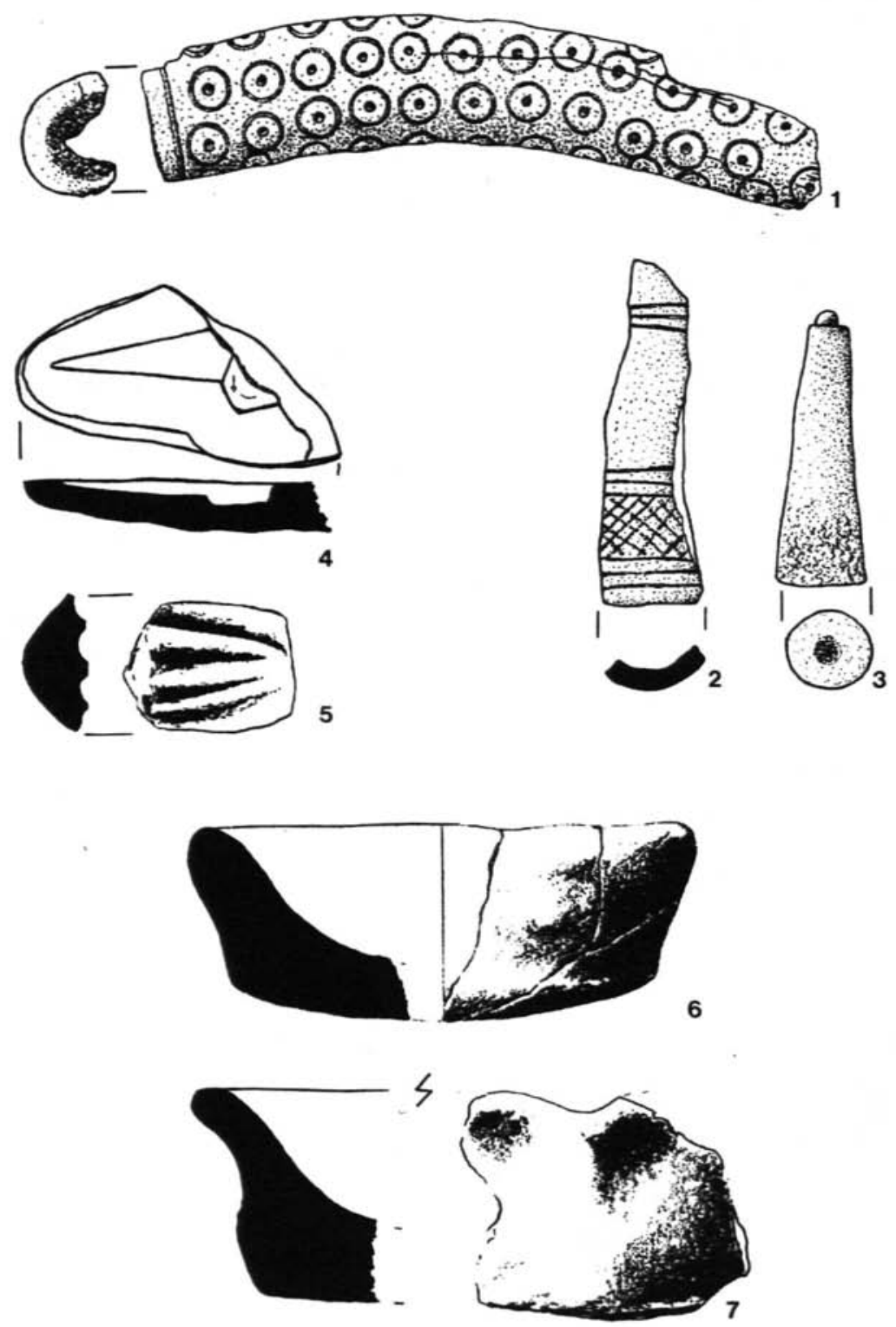

Fig.5. Elementos de hueso y cuerna (1-3), moldes de piedra (4-5) y crisoles (6-7): 1-3 según Ruibal y González Álvarez; 4 inédito; 5-7 de López González et alii, 1999. 
de tipos "omega" (30c1b Feugère; 35.1b de Erice) y de "charnela" (Iturissa 22b Feugère; 25.4b de Erice Lacabe, 1995) son exponentes del proceso de romanización del Noroeste penisular desde comienzos del siglo I a. C., las primeras, a comienzos del II d.C., las segundas (Erice Lacabe, 1995, 156 ss y 213 ss) - (Fig. 4.1 y 9). Otras reflejan contextos indígenas contemporáneos (Fig. 4.2 y 5), como las de esquema de La Tène I de tipos "caballito " y "torre", típicas de la Meseta Norte desde el siglo IV a finales del II a.C. (Argente, 1994, 88 y 93; Almagro-Gorbea y Torres, 1999, 213 ss). Ambas remiten a tipos tardíos muy conocidos en Numancia, donde se localiza el único paralelo de un raro ejemplar de fíbula zoomorfa "de hipocampo" (Fig. 4.3), tipo 31 de Erice Lacabe, y cuya fecha siguiendo a Riha más que a Feugère se situaría a inicios del siglo II d. C. (Erice, 1995, 199; Riha, 1979).

En general todas pueden datarse con facilidad desde los inicios del siglo I a.C. a los comienzos del II d. C., una datación extrapolable a un pequeño fragmento de tubito de electrón u oricalco, decorado con sucesiones de puntos repujados a imitación de un remoto granulado orientalizante (fig. 4.4), quizá en línea con el hallado en La Campa Torres (Maya y Cuesta, 1995, 120), y a numerosas agujas, argollas, remaches, asas, etc. de una rica producción broncínea de elementos menores que tienen su reflejo en moldes, yunques y crisoles (fig. 5).

\section{CONCLUSIONES: EL LLAGÚ, UN RETO NECESARIO}

Es conocido que el bagaje de la investigación protohistórica en el Oeste y Norte de la Península aporta, con cierta facilidad de identificación, el emplazamiento de un gran número de castros frente a otros testimonios culturales contemporáneos, cómo las mismas necrópolis. Sus emplazamientos en lugares destacados por la orografía (horcajos, farallones, cerros-atalayas, etc.) y la presencia de masivas obras de fortificación adaptadas al terreno, y otras razones políticas no menos trascendentes, permiten comprender porqué la Investigación volcó su esfuerzo en localizar e identificar poblados hasta décadas recientes, más como ejercicio sumativo sobre un mapa de dispersión de puntos que como intento de sistematización organizada que permitiera un conocimiento previsible de las pautas de colonización y explotación del territorio.

Sin embargo, desde esta óptica se realizaron, desde finales de los años setenta, trascendentes trabajos sobre El Caurel (Luzón y Sánchez-Palencia, 1980) y otras comarcas gallegas (v. gr., Carballo, 1993) y, sobre estos planteamientos, se desarrollaron diferentes análisis del poblamiento castreño, tanto en Asturias (Camino, 1995; Villa, 1999) como en el Oeste en general (Berrocal-Rangel, 1992 y 1998; Martín Bravo, 1999; Álvarez Sanchís, 1999, etc.).

En nuestra opinión, este enfoque, que considera el castro como "paradigma" del conocimiento "prerromano", ha puesto de manifiesto con toda su crudeza una patente necesidad, la falta de excavaciones de poblados en extensión, con técnicas y medios modernos, porque la gran mayoría de los ensayos se han sustentado sobre una base prospectora y sobre sondeos de urgencias, y hallazgos "casuales", aportes de un caudal informativo complementario importante, pero que no puede configurar el mayor contingente de 
datos sin distorsionar la base de conocimientos necesaria para cualquier trabajo de deducción. Aunque no caben dudas que, para paliar esta deficiencia, se ha incrementado positivamente la valoración de los emplazamientos y de los entornos, aún son escasas las publicaciones con prospecciones sistemáticas y, mucho más, las excavaciones en extensión con algo más que unidades de habitación aisladas e informes anexos de fauna y flora, cuando los hay.

Por todo ello, parecen oportunas las palabras del equipo de excavaciones responsables de la actuación de 1998: "el análisis microespacial de las distintas fases de ocupación está aún por resolver. Su estudio, que debe hacerse necesariamente sobre una superficie mucho más amplia del asentamiento, proporcionaría información acerca de las formas de vida y de cómo éstas evolucionarían en el tiempo. Esta visión global del proceso histórico es en definitiva el objetivo final de la investigación arqueológica y su análisis debe ser la base sobre la que se realicen posteriores investigaciones de cualquier otro tipo" (López González et alii, 1999, 251).

Que los astures eran "bárbaros" no caben dudas, pero en el estricto significado clásico de tal palabra. Porque, la Romanidad destacada por la reciente investigación fue resultado, no de la imposición rápida de un nuevo estilo de vida, sino de la convergencia de dos sistemas de complejidad de evolución paralela, aunque claramente desfasados. La convergencia se alcanzó tras un proceso lento, de varios siglos y de varios factores, o autores, entre los que la relación con las tropas "romanizadas" y el interés por los metales, básicamente por el oro, fueron fundamentales para su consolidación (Fernández-Posse, 1998, 233234).

Quedan por aclarar muchas cuestiones sobre el cuándo y el cómo se gestó dicha Romanidad. A la consecución de respuestas válidas para tales preguntas, el proyecto Castiellu de Llagú tiene la obligación de poder contribuir en un futuro inmediato. 


\section{BIBLIOGRAFIA}

ALMAGRO-GORBEA, M.; TORRES, M., 1999: Las fibulas de jinete y de caballito. Aproximaciones a la élite ecuestre de la Hispania céltica., Extra Complutum, 8, Madrid.

ALONSO, J.L.; ALLER, J.; BASTIDA, F.; MARCOS, A.; MARQUÍNEZ, J.; PÉREZ-ESTAÚN, A.; PULGAR, J.A., 1991: Avilés. Memoria explicativa de la boja 2 (3-1) del Mapa Geológico de España., Inst. Tecnológico Geominero de España, Madrid.

ÁLVAREZ SANCHÍS, J., 1999: Los Vettones. Bibliotheca Archaeologica Hispana, 1, Madrid.

ARGENTE OLIVER, J.L., 1994: Las fibulas de la Edad del Hierro en la Meseta Oriental., EAE, 168, Madrid.

ASENSIO AMOR, I., 1970: "Rasgos geomorfológicos de la zona litoral galaico-astúrica en relación con las oscilaciones glacio-eustáticas”, Estudios Geológicos, 26, 29-91.

BERROCAL-RANGEL, L., 1992: Los Pueblos Célticos del Suroeste de la Península Ibérica. Extra Complutum, 2, Madrid.

BERROCAL-RANGEL, L., 1998: La Beturia, un territorio prerromano en la Baja Extremadura, Arte y Arqueología, 20, Badajoz.

BERROCAL-RANGEL, L.; MARTÍNEZ SECO, P.; RUIZ TRIVIÑO, C., en prensa: "Cuestiones de metodología instrumental en Arqueoogía de castros. El Proyecto Llagú (Latores, Oviedo)." En VILLA VALDÉS, A., ed., Formación y Desarrollo de la Cultura Castreña (Actas Coloquios de Arqueología Cuenca del Navia, Navia, 2000).

CAMINO MAYOR, J., 1995: "Excavaciones arqueológicas en los castros de la ría de Villaviciosa: apuntes para una sistematización de la Edad del Hierro.", Excavaciones Arqueológicas en Asturias 1991-1994, 1, 117-126.

CAMINO MAYOR, J., 2000: "Las murallas compartimentadas en los castros de Asturias: bases para un debate." Archivo Español de Arqueología, 73, 27-42.

CAMINO MAYOR, J., en prensa: "Algunos comentarios sobre las pautas territoriales y sociales de los castros del Oriente de Asturias", En VILLA VALDÉS, A., ed., Formación y Desarrollo de la Cultura Castreña (Actas Coloquios de Arqueología Cuenca del Navia, Navia, 2000).

CARBALLO ARCEO, L.X., 1993: "Espacio e povoamento castrexo de Galiza.", Concepcións espaciais e estratexias territoriais na Historia da Galicia, 55-82, Santiago.

CARROCERA, E., 1995: "El territorio de los astures: los castros", Catálogo de la Exposición Astures, 53-65, Gijón.

CARROCERA, E.; CAMINO, J., 1996: "La Edad del Hierro en el territorio histórico de los astures o la realidad de un espacio administrativo romano.", en FERNÁNDEZ OCHOA, ed., Actas Coloquio Int. Los Finisterres atlánticos en la Antigüedad, 57-60, Gijón.

ERICE LACABE, R., 1995: Las fibulas del Nordeste de la Península Ibérica: siglos I a.E. al IV d. E., Institución Fernando el Católico, Zaragoza.

ESTRADA, R., 1997: "El castro de Llagú. Un bien cultural en peligro", Revista de Arqueologia, 195, 6-9.

ESTRADA, R., 1999: "Reseña de la carta arqueológica del Concejo de Grado", Excavaciones Arqueológicas en Asturias 1995-1998, 4, 315-318. 
FERNÁNDEZ OCHOA, C., 1981: Arqueología romana de Asturias. Tesis doctoral mecanografiada, Universidad Autónoma de Madrid.

FERNÁNDEZ OCHOA, C., 1982: Asturias en la época romana, Madrid.

FERNÁNDEZ OCHOA, C., 1987: "La cultura castreña de los pueblos del norte y noroeste de la segunda Edad del Hierro", en BENDALA, M., ed., Historia General de España y América, I2. De la Protobistoria a la Conquista romana, 357-379, Madrid.

FERNÁNDEZ OCHOA, C.; MORILLO CERDÁN, A., 1999: La tierra de los astures. Nuevas perspectivas sobre la implantación romana en la antigua Asturia. Gijón.

FERNÁNDEZ-POSE, M.D., 1998: La investigación protobistórica en la Meseta y Galicia. Arqueología Prehistórica 1, Síntesis, Madrid.

GARCÍA Y BELLIDO, A., 1971: "El castro de Coaña", Arcbivo Español de Arqueología, 42, Madrid. GONZÁLEZ RODRÍGUEZ, M.C., 1997: Los astures y los cántabros vandinienses. Vitoria.

GONZÁLEZ Y FERNÁNDEZ VALLÉS, J.M., 1976: Miscelānea Histórica Asturiana. Oviedo.

HARRIS, E.C., 1991: Principios de Estratigrafía Arqueológica, Crítica Arqueología, Barcelona.

JULIVERT, M.; MARCOS, A., 1981: Cangas del Narcea. Memoria explicatica de la boja 9 del Mapa Geológico de España, Inst. Geológico y Minero, Madrid.

LÓPEZ GONZÁLEZ, L.F.; ÁLVAREZ GONZÁLEZ, Y.; LÓPEZ MARCOS, M.A., 1999: "Excavación en el Castro de Llagú, Latores (Oviedo 1998). Avance de sus resultados", Excavaciones Arqueológicas en Asturias 1995-1998, 4, 237-251.

LUZÓN NOGUÉ, J.M.; SÁNCHEZ-PALENCIA RAMOS, J., 1980: El Caurel. Excavaciones Arqueológicas en España, 110, Madrid.

MAPA DE SUELOS, 1988: Memoria del Mapa de suelos y aprovechamientos del Principado de Asturias, Publicaciones Agrarias, Pesqueras y Alimentarias, Ministerio de Agricultua, Madrid.

MARTIN BRAVO, A.M., 1999: Los origenes de Lusitania. El I Milenio en la Alta Extremadura, Bibliotheca Archaeologica Hispana, 2, Madrid.

MAYA, J.L., 1987-1988: La cultura material de los castros asturianos. Estudios de la Antigüedad, 4/5, Bellaterra, Barcelona.

MAYA, J.L.; CUESTA, F., 1995: "Guía de la Campa Torres", en FERNÁNDEZ OCHOA, C.; y FERNÁNDEZ-MIRANDA, M., eds., Astures. Pueblos y culturas en la frontera del Imperio Romano, Catálogo de la Exposición, 111-152, Gijón.

MAYA, J.L.; MESTRES, J. S., 1998: "Dataciones prerromanas del Castiellu de Llagú (Latores, Oviedo).", Revista de Arqueología, 211, 6-11.

RIHA, E., 1978: Die römische Fibeln aus Augst und Kaiseraug, Forschungen in Augst, 3, Augst.

RUIBAL MARTÍNEZ, J.; GONZÁLEZ ÁLVAREZ, M.L., 1994: Memoria de la excavación de la primera fase del yacimiento de Castiellu de Llagú (Latores, Oviedo). Memoria inédita.

RUIBAL MARTÍNEZ, J.; GONZÁLEZ ÁLVAREZ, M.L., 1996: Excavaciones arqueológicas en el castro de Castiellu de Llagú (Latores, Oviedo). Memoria inédita.

SÁNCHEZ-PALENCIA, F.J. 1995: "Minería y metalurgia de la región astur en la Antigüedad", Catálogo de la Exposición Astures, 141-147, Gijón.

VILLA VALDÉS, A., 1999: "Castro del Chao Samartín (Grandas de Salime): Tres años de investigación arqueológica", Excavaciones Arqueológicas en Asturias 1995-1998, 4, 111-123. 